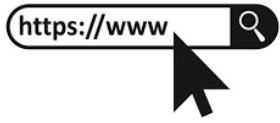

Research article

\title{
PHARMACY RESPONSE TO NATURAL DISASTERS
}

\author{
Miljan Adamović ${ }^{1}$, Stefan Milojević2 , Srđan Nikolovski ${ }^{3}$, Snežana Knežević ${ }^{4}$ \\ ${ }^{1}$ Pharmacy institution “ZDRAVLJE LEK” Kragujevac, Serbia; zdravljelek@gmail.com \\ ${ }^{2}$ Audit, accounting, financial and consulting services company „Moodys Standards, Ltd., \\ Belgrade, Serbia; aviation.adviser@gmail.com \\ ${ }^{3}$ University of Belgrade; Faculty of Medicine; srdjannikolovski@gmail.com \\ ${ }^{4}$ University of Belgrade, Faculty of organizational Sciences; snezana.knezevic@fon.bg.ac.rs \\ *Correspondence: srdjannikolovski@gmail.com; Tel.: +381-65-5548-883
}

\begin{abstract}
Pharmacy institutions are one of the key elements in modern healthcare systems throughout the world. Pharmacies can be a part of the public healthcare system at primary, or secondary and tertiary levels. Also, pharmacies can be founded as a private institution, having the same roles and amount of responsibility compared to public ones. The aim of this paper was to examine the role of pharmacies in emergency and catastrophic events. The crucial role of pharmacies is especially emphasized in emergency and catastrophic events when the majority of other healthcare institutions are mobilized in providing more important healthcare activities and services. In those instances, pharmacies represent a primary connection between the patients and community in general and the healthcare system. Proper fulfillment of necessary requirements for registration of pharmacy institutions is essential for its successful operation, but continuous education of pharmacy staff plays an equally important role. The most recent events, such as the COVID-19 pandemic, are one additional evidence confirming that pharmacy institutions are an irreplaceable link in the healthcare system chain continuously serving as a first-line connection with all individuals in a community.
\end{abstract}

Keywords: pharmacy, natural disasters, emergency, response

\section{Introduction}

The role of pharmacists in disaster risk management is undoubtedly enormous. During and after disasters or other emergencies, it is especially important to continuously supply pharmaceutical products and medical supplies in order to provide an effective response to these specific circumstances, to alleviate the difficulties that accompany emergency situations, and to reduce damage as much as possible. To this end, the importance of locally available pharmacy staff, both licensed pharmacists and unlicensed support staff in carrying out activities during emergencies is emphasized. 
Emergencies and disasters represent two major threats to the healthcare systems of any country, and at the same time, together, they are a global threat. Pharmacists have a major impact on disaster preparedness and response because they are involved in both clinical and non-clinical roles (Aburas \& Thamir, 2020).

In modern approaches to disaster management, disasters are spatial-related; the distribution, severity, type and population affected by the disasters are taken into account (Ocal et al., 2021).

The article is structured as follows. The first section presents a look at pharmacy institutions in the Republic of Serbia. The second section presents the role and significance of pharmacy institutions in emergency situations. The last section includes the conclusions.

\section{A look at pharmacy institutions in the Republic of Serbia}

Organizing and performing pharmacy activities in the Republic of Serbia is performed in accordance with the law governing health insurance, the law governing drugs, and the law governing medical devices, as well as the Guidelines of Good Pharmacy Practice, issued by the Pharmaceutical Chamber of Serbia (hereinafter: the Pharmaceutical Chamber), with the consent of the Minister of health (Law on Health Care, Article 221, "Official Gazette of the Republic of Serbia", No. 25/2019)

Pharmacy activity is a healthcare activity that provides pharmaceutical health care to citizens, and which is implemented through the healthcare system and performed at the primary, secondary, and tertiary levels of health care and in private practice (Law on Health Care, Article 201, "Official Gazette of the Republic of Serbia", No. 25/2019).

The Law on Health Care, among other things, prescribes what is and what is included in the pharmacy activity, as well as what are the forms of organization in which the pharmacy activity is performed. A pharmacy can take the form of a healthcare institution and a private practice institution. The choice between these two forms will depend on the staff, space, and equipment, and what is also important to keep in mind is that private practice takes the form of entrepreneurial activity. Pursuant to the mentioned law, the pharmacy activity is performed by:

- pharmacy institution;

- pharmacy of the community healthcare center or as an organizational part of another healthcare institution at the primary level of health care;

- pharmacy as an organizational part of a health institution at the secondary or tertiary level of health care, or a healthcare institution that performs activities at several levels of health care (hospital pharmacy);

- private practice pharmacy.

The pharmacy institution, as well as all other privately owned healthcare institutions, pursuant to the law, is established by a legal entity or an individual, under the conditions prescribed by the Law and bylaws adopted for the implementation of the Law (Rule book on detailed conditions for performing healthcare activities in healthcare institutions and other forms of healthcare service). Therefore, for the establishment of a pharmacy institution (founder - a legal entity or an individual), the professional or other personal qualifications of the founder are not important, but it is necessary for the founder, in addition to submitting the founding act, to provide conditions prescribed in terms of staff, premises, equipment, and medicines. 
Any of the types of health care institutions determined by the Law, as well as any form of private practice, may be established and may perform healthcare activities if it meets the conditions prescribed by the Law and the Rule book on detailed conditions for performing healthcare activities in healthcare institutions and other forms of healthcare service, concerning staff, equipment, space, and medicinal products.

At the request of the founder, the fulfillment of the prescribed conditions is assessed by the health inspector of the Ministry of Health, by a decision, in accordance with the Law on Healthcare and the Law on General Administrative Procedure, on the basis of which the pharmacy institution is entered in the register of the Business Registers Agency, when it acquires the right to operate.

The resilience of small and medium-sized enterprises (SMEs) is considered a prerequisite for sustainable development at both local and national levels, but they are also the most vulnerable as a result of financial, technological, and administrative constraints, with most SMEs lacking even basic knowledge of disaster preparedness and techniques of responses (Mavrodieva et al., 2019).

\section{Role and significance of pharmacy institutions in emergency situations}

Pharmacists and their counterparts generally receive limited training in disaster medicine and emergency preparedness as part of their initial qualifications, even in countries with well-developed vocational education programs. In this context, Alkhalili et al. (2017) point out that pharmacy efforts have also traditionally focused on medical supply activities, rather than on general emergency preparedness. In order for pharmacists to be able to adequately respond to disasters, which is essential for ensuring the continued health and well-being of the local population, pharmacists need to be prepared for disasters in order to successfully implement pharmacy services (McCourt, et al., 2020). The pharmacist's readiness depends, among other factors, on the vocational education program and general emergency preparedness.

The past decade has seen rapid changes in the climate system with an increased risk of extreme weather events, which has encouraged the wider community to properly recognize the important role of primary health care. In this context, there is no doubt that pharmacists have a special place in the implementation of activities during natural disasters, and in this regard, they need to be fully involved in the process of disaster management planning, to minimize the risk of their consequences (Mak \& Singleton, 2016).

Breakdown of healthcare systems is a common outcome of natural disasters, which include tropical cyclones. In such circumstances, pharmacists have direct communication with the population that may be at risk of disasters and there is no need to make an appointment. It is therefore important that pharmacists develop trust with the community, and it is undeniable that they can play a key role in providing health care in the communities they serve during disasters (Vhiriri et al., 2021). In the circumstances of a natural disaster and pandemic, the need for cohesive departmental communication, staff flexibility, prioritization of teamwork, and external collaboration are crucial (Zuckerman et al., 2020).

Pharmacists play a very important role in the accurate identification, provision, and use of medicines that are of particular importance in terms of the medical care used by disaster victims. During disasters, it is important to focus on accomplishing tasks by defining employee roles, establishing chains of communication, delegating authority to competent persons, re- 
stricting decision-making by non-commanders, and defining pharmacy participation limits in disasters (Moore, 1979).

There are also specific issues that need to be considered according to the types of disasters. For example, during the events of Hurricane "Florence", suboptimal functionality of the pharmacy for coastal areas was discovered during the period of disaster response (Sharpe \& Clennon, 2020). In order to prevent such situations from recurring, hurricane preparedness and infrastructure strengthening plans need to be specifically dimensioned for local pharmacies in hurricane-prone areas. Furthermore, floods are one of the most common and extreme threats today, so it is necessary to evaluate the vulnerability of relevant organizations to the danger of floods (Aktar et al., 2021). Perić \& Cetković (2019) state that, having in mind that floods are very common in the Republic of Serbia, as well as that they directly endanger people's lives and health, their property, and the environment, it is necessary to consider how an individual perceives risk from natural disasters caused by floods. In addition, Cvetković (2019) emphasizes the importance of building fire risk perception.

Pharmacists are in a unique position in the community to help disaster-stricken patients. However, what is specific to them is that their roles in disasters have been identified based on their own experiences and networks (Watson et al., 2019). Adopting the role of pharmacists in non-pharmaceutical supply may present a problem of accepting paradigm shift in non-traditional roles. Possible staff shortages in future disasters may change pharmacists' approach to disaster management (Ford et al., 2013). The role of pharmacists in disasters has not changed significantly since the 1960s. Pharmaceutical procurement remains their desirable role, while patient management and response integration roles are diminishing in the context of common, geographically widespread disasters (Raza et al., 2021).

COVID-19 pandemic as a public health emergency evolved fast and put pharmacies at the front lines. The fact that further intensifies this emergency situation is it's a potential connection with ecology disasters question (Nikolovski, 2021a; Murányi \& Varga, 2021), and new COVID-19 variants of concern which can significantly vary leaving not enough time for the population to adapt (Nikolovski, 2021b).

The question is often asked: what are the roles and added value of intensive care pharmacists during the COVID-19 pandemic period? Their missions have evolved although they have remained focused on providing health care to patients (Lemtiri et al., 2020). It is interesting to see the perception of different groups of employees (according to professions) in Serbia on Public trust when it comes to the COVID-19 pandemic (Markovic et al., 2020). It is out of paramount importance for disaster preparedness as well, since the central point of public trust is a government which is also a central point in coordinating disaster response measures.

\section{Conclusion}

The pharmacy profession has a significant role in the efficient management of activities during and after the disaster event, and in the event of other emergencies. Therefore, pharmacists are especially expected to provide an effective response to emergencies. In addition, there is a need for effective communication and cooperation in general between the members of the pharmacy team in situations that can be described as "catastrophic".

All stages of development of pharmacy institutions, starting from fulfilling the requirements needed to the initiation of business and including continuing education of staff and adaptation according to the population needs are essential for the existence and accomplishing the unique 
role those institutions have. Public health emergencies are certainly the most representative examples of emergency situations in which pharmacies have a specific role and when those institutions are pushed to the front line, serving as an always-available primary contact to patients and other community members and linking them to the healthcare system.

\section{References}

1. Aburas, W., \& Alshammari, T.M. (2020). Pharmacist's roles in emergency and disasters: COVID-19 as an example. Saudi Pharmaceutical Journal, S1319016420302681-. doi: 10.1016/j.jsps.2020.11.006.

2. Ocal, A. (2021). Disaster management in Turkey: a spatial approach. International Journal of Disaster Risk Management, 3(1), 15-22. https://doi.org/10.18485/ijdrm.2021.3.1.2.

3. Law on Health Care, "Official Gazette of the Republic of Serbia”, No. 25/2019.

4. Rule book on detailed conditions for performing healthcare activities in healthcare institutions and other forms of healthcare service, no 43/2006, 112/2009, 50/2010, 79/2011, 10/2012, 119/2012, 22/2013 i 16/2018.

5. Zakon o opštem upravnom postupku, „Sl. glasnik RS”, br. 18/2016 i 95/2018.

6. Mavrodieva, A., Budiarti, D., Yu, Z., Pasha, F., \& Shaw, R. (2019). Governmental Incentivization for SMEs' Engagement in Disaster Resilience in Southeast Asia. International Journal of Disaster Risk Management, 1(1), 32-50. https://doi.org/10.18485/ijdrm.2019.1.1.2.

7. Alkhalili, M., Ma, J., \& Grenier, S. (2017). Defining Roles for Pharmacy Personnel in Disaster Response and Emergency Preparedness. Disaster Medicine and Public Health Preparedness, 11(4), 496-504. doi:10.1017/dmp.2016.172.

8. McCourt, E., Singleton, J., Tippett, V., Nissen, L. (2020). Disaster preparedness amongst pharmacists and pharmacy students: a systematic literature review. International Journal of Pharmacy Practice, doi:10.1111/ijpp.12669.

9. Mak, P.W., \& Singleton, J. (2016). Burning questions: Exploring the impact of natural disasters on community pharmacies. Research in Social and Administrative Pharmacy. doi: 10.1016/j.sapharm.2015.12.015.

10. Vhiriri E.P., Msimang A., Laubscher R.K., Irwin Y., Chiwanza F., Tandlich R. (2021). Natural Disasters and the Role of Pharmacists: A Focus on Policy and Protocols in South Africa. In: Nhamo G., Dube K. (eds) Cyclones in Southern Africa. Sustainable Development Goals Series. Springer, Cham. https://doi.org/10.1007/978-3-030-74262-1_10.

11. Raza, M.A., Aziz, S., Noreen, M., Raza, S.M. (2021). Role of Pharmacist in Disaster Management: A Quantitative Content Analysis Approach, Innovations in pharmacy, 12(4), 1-19. https://doi.org/10.24926/iip.v12i4.4359.

12. Moore, T.D. (1979). Administrative approach to disaster preparedness in the pharmacy. American Journal of Health-System Pharmacy, 36(10), 1337-1341. doi:10.1093/ ajhp/36.10.1337.

13. Sharpe \& Clennon (2019). Pharmacy Functionality During the Hurricane Florence Disaster. Disaster Medicine and Public Health Preparedness , 14(1), 93 - 102. https://doi. org/10.1017/dmp.2019.114.

14. Aktar, M. A., Shohani, K., Hasan, M. N., \& Hasan, M. K. (2021). Flood Vulnerability Assessment by Flood Vulnerability Index (FVI) Method: A Study on Sirajganj Sadar Upazila. International Journal of Disaster Risk Management, 3(1), 1-14. https://doi.org/10.18485/ ijdrm.2021.3.1.1. 
15. Perić, J., \& Cvetković, V. (2019). Demographic, socio-economic and phycological perspective of risk perception from disasters caused by floods: case study Belgrade. International Journal of Disaster Risk Management, 1(2), 31-45. https://doi.org/10.18485/ijdrm.2019.1.2.3. 16. Cvetković, V. (2019). Risk perception of building fires in Belgrade. International Journal of Disaster Risk Management, 1(1), 81-91.

17. Watson, Kaitlyn E.; Singleton, Judith A.; Tippett, Vivienne; Nissen, Lisa M.; Murakami, Michio (2019). Defining pharmacists' roles in disasters: A Delphi study. PLOS ONE, 14(12),. doi: 10.1371/journal.pone.0227132

18. Ford, H., Dallas, C.E., Harris, C. (2013). Examining roles pharmacists assume in disasters: a content analytic approach. Disaster Med Public Health Prep. 7(6), 563-72. doi: 10.1017/ dmp.2013.99.

19. Zuckerman, A.D., Patel, P.C., Sullivan, M., Potts, A., Knostman, M., Humphreys, E., Oâeal, M., Bryant, A., Torr, D.K., Lobo, B., Peek, G., Kelley, T., Manfred, J., Tomichek, J., Crothers, G., Catlin, R., Brumagin, H.E., Hughes, L., Hayman, J. (2020). From natural disaster to pandemic: A health-system pharmacy rises to the challenge. American Journal of Health-System Pharmacy, doi:10.1093/ajhp/zxaa180.

20. Nikolovski, S. (2021a, December 24-25). Pandemic, Ecology, and Human Rights - A Bermuda Triangle of COVID-19 [Conference presentation]. $3^{\text {rd }}$ International Conference on Medical \& Health Sciences, Bingol, Turkey.

21. Murányi, A., \& Varga, B. (2021). Relationship Between the COVID-19 Pandemic and Ecological, Economic, and Social Conditions. Frontiers in public health, 9, 694191. https:// doi.org/10.3389/fpubh.2021.694191

22. Nikolovski, S. (2021b, December 24-25). Omicron SARS-CoV-2 Variant - Transmissibility, Virulence, Illness Severity, Prevention, and Vaccine Efficacy Compared to Previous and Future Variants [Conference presentation]. $3^{\text {rd }}$ International Conference on Medical \& Health Sciences, Bingol, Turkey.

23. Lemtiri, J., Matusik, E., Cousein, E., Lambiotte, F., Elbeki, N. (2020). The role of the critical care pharmacist during the COVID-19 pandemic: Lemtiri J, et al. The role of the critical care pharmacist during the COVID-19 pandemic. Ann Pharm Fr (2020), doi.org/10.1016/j. pharma.2020.09.001.

24. Marković, I., Nikolovski, S., Milojević, S., Živković, D., Knežević, S., Mitrović, A., Fišer, Z, Đurđević, D. (2020). Public Trust and Media Influence on Anxiety and Depression Levels Among Skilled Workers During the COVID-19 Outbreak in Serbia). Vojnosanitetski pregled. Military-medical and pharmaceutical review, 77(11),1201-1209. DOI: 10.2298/ VSP200713108M.

Author Contributions:

Author Contributions: M.A was responsible for the overall coordination among the authors, for the body and flow of the paper, and for all editing. M.A., S.M., S.N. and S.K. have provided some input and close to equal input in all chapters of the paper.

Conflicts of Interest:

"The authors declare no conflict of interest." 